\title{
Evidence of vascular disease from CT scanning in late onset epilepsy
}

\author{
SD SHORVON, RW GILLIATT, TCS COX, YL YU \\ From the Institute of Neurology and The National Hospital for Nervous Diseases, Queen Square, \\ London, $U K$
}

SUMmaRY The CT scans of 74 patients presenting with late-onset epilepsy not due to cerebral tumour were compared with those of an age and sex-matched control group for evidence of cerebral vascular disease. Changes in the scan indicative of cerebral atrophy (enlarged ventricles and cortical sulci) were seen in similar numbers in both patients and controls. However, the scans revealed a highly significant excess of ischaemic lesions in the epileptic patients, in the form of discrete areas of infarction and low attenuation of the periventricular white matter. These changes, which were only seen in two of the controls, were present in 13 of the epileptic patients. The median age at the onset of epilepsy in the 13 patients with ischaemic lesions was 62 years, and they showed an increased incidence of systemic vascular disease and of abnormal neurological signs. In six of the 13 cases, however, clinical examination was normal and CT scanning provided the only evidence of underlying vascular disease.

While it is generally accepted that cerebral vascular disease sometimes causes epilepsy in late life, it may be difficult to decide in an individual patient whether the presence of vascular disease (either cerebral or generalised) is related to the patient's epilepsy or whether it is a chance finding related to the patient's age. In this prospective study we have examined the CT scan appearances in a group of patients with epileptic seizures commencing over the age of 40 years and in age-matched controls, in order to discover whether evidence of underlying vascular disease in late-onset epilepsy is found more often than in a control group of comparable age.

\section{Methods}

\section{Patients with epileptic seizures}

All new outpatients referred over an 18-month period (July, 1981-January 1983) to the National Hospital for Nervous Diseases, Queen Square, or to one of us (RWG) at the Middlesex Hospital, with a history of one or more epileptic seizures commencing after the age of 40 years, were identified after their first clinic visit, and their case notes reviewed. Patients presenting with other symptoms such as

Address for reprint requests: Prof RW Gilliatt, The National Hospital for Nervous Diseases, Queen Sq, London WC1N 3BG, UK.

Received 19 August 1983

Accepted 24 September 1983 dementia, dysphasia or paresis, who were also found to have seizures, were not included in the study. However, patients referred for the investigation of epilepsy, who were subsequently found on clinical examination to have minor neurological abnormalities were accepted. In addition to a CT scan, a routine 16-channel EEG was available in nearly all cases, and an ECG in approximately half of them. Prolonged monitoring of the EEG and ECG was performed on a few occasions, using the system described by Cull et al. ${ }^{1}$ When there was doubt after investigation as to whether an attack was syncopal or epileptic, the case was rejected.

\section{Controls subjects}

Controls of similar age and sex were selected from patients with spinal cord or neuromuscular disorders who were inpatients or outpatients during the period of the study. The clinical diagnoses in the control subjects are given in table 1 . Patients with neuromuscular disorders which might be associated with hypertension or arterial degeneration were

Table 1 Control group: clinical diagnosis

\begin{tabular}{lc}
\hline Primary muscle disease & 7 \\
Myasthenia gravis & 4 \\
Polyneuropathy & 11 \\
Entrapment neuropathy & 11 \\
Spinal cord and root lesions due to intervertebral & 17 \\
disc degeneration & 10 \\
Pain syndromes & 4 \\
Spinal AVM/Neurofibroma & 1 \\
Post-viral myelitis & 3 \\
Motor neurone disease & 6 \\
\hline Spinal muscular atrophy & \\
\hline "Includes post-herpetic neuralgia, perineal pain, restless legs
\end{tabular}


not accepted; cases of diabetic peripheral neuropathy, for example, were excluded.

\section{CT scanning}

CT scanning was carried out using an EMI 1010 or 5005 machine. Consecutive slices $10 \mathrm{~mm}$ thick were examined parallel to the orbito-meatal line, covering regions from the posterior fossa to the highest hemisphere sulci. The diminution factors of the machines were determined initially by scanning catheter markers $1 \mathrm{~cm}$ apart.

The scans were assessed by two of us (TCSC and YLY) without knowing whether they came from epileptic patients or from controls. Subjective assessments were made of: (1) The presence of ischaemic lesions, classified as (a) Lacunar infarcts: discrete deeply situated low-density lesions less than $1 \mathrm{~cm}$ in diameter, (b) Cerebral infarcts: discrete lowdensity lesions greater than $1 \mathrm{~cm}$ in diameter, (c) White matter low attenuation: ill-defined low-density lesions situated around the lateral ventricles, and (2) The presence of cerebral atrophy classified as (a) Generalised (affecting ventricles, sulci and Sylvian fissures), (b) Peripheral (affecting mainly sulci and Sylvian fissures), (c) Central (affecting mainly ventricles), (d) Focal. The atrophy was graded as nil, mild or severe.

In addition to the subjective assessment above, measurements were made of anterior horn width, septum-caudate distance, minimum cella media distance, third ventricular width, Evans ratio and cella media index, as described by Gyldensted. ${ }^{2}$

\section{Results}

Eighty-nine patients with epileptic seizures commencing over the age of 40 years were available for study. In 10 patients the CT scan showed a cerebral tumour, and in a further five patients a CT scan either was not done or was technically unsatisfactory. These two groups will not be considered in the present analysis. There remained 74 patients in whom the cause of the epilepsy remained uncertain. In two of these patients there was a history of head injury preceding the onset of the epilepsy by 14 and 15 years respectively. In three patients an excessive alcohol intake was established or suspected, and in five cases there was a family history of epilepsy in a first-degree relative.

The age and sex distribution of the 74 patients is shown in table 2 , and it can be seen that there was an excess of males over females throughout the age range, the disproportion being most marked in those aged 70 and over. The control group contained patients of similar age and sex (table 2).

Features indicative of cardiac or systemic vascular disease are shown in table 3 , and it can be seen that there were no differences between the patients and the controls. In four patients and two controls more than one of the features listed in table 3 were present, so that the number of affected individuals was 15 in each group.
Table 2 Age and sex distribution in 74 patients and controls

\begin{tabular}{llllll}
\hline $\begin{array}{l}\text { Age range } \\
(y r)\end{array}$ & \multicolumn{2}{l}{ No. of patients } & & \multicolumn{2}{l}{ No. of controls } \\
\cline { 2 - 3 } \cline { 5 - 6 } & Male & Female & & Male & Female \\
\hline $40-54$ & 18 & 9 & & 16 & 8 \\
$55-69$ & 22 & 13 & & 22 & 14 \\
$70-84$ & 9 & 3 & & 3 \\
Total & 49 & 25 & & 49 & 25 \\
\hline
\end{tabular}

Table 3 Cardiac and systemic vascular features in 74 patients and controls

\begin{tabular}{lcc}
\hline & $\begin{array}{l}\text { In } \\
\text { patients }\end{array}$ & $\begin{array}{l}\text { In } \\
\text { controls }\end{array}$ \\
\hline Hypertension* & 9 & 5 \\
Ischaemic heart disease & 3 & 6 \\
Rheumatic heart disease & 1 & 2 \\
Atrial fibrillation & 1 & 2 \\
Retinal vessel occlusion & 1 & 1 \\
Intermittent calf claudication & 3 & 0 \\
Asymptomatic carotid bruit & 1 & 1 \\
Total & 19 & 17 \\
No. of affected subjects: & $15(20 \%)$ & $15(20 \%)$ \\
\hline (In 4 patients and 2 controls more than one vascular feature was \\
present.) *Diastolic pressure >100 mmHg and/or systolic pressure \\
>180 mmHg at the first measurement
\end{tabular}

Table 4 CT scan changes in 74 patients and controls

\begin{tabular}{lcc}
\hline CT findings & $\begin{array}{l}\text { In } \\
\text { patients }\end{array}$ & $\begin{array}{l}\text { In } \\
\text { controls }\end{array}$ \\
\hline Ischaemic lesions: & 3 & 0 \\
$\quad$ Lacunar infarction alone & 1 & 1 \\
$\quad$ Cerebral infarction alone & 3 & 1 \\
White-matter low & 6 & 0 \\
$\quad$ attenuation alone & 13 & 2 \\
Combinations of the above & & \\
$\quad$ Total & & \\
Atrophy grade: & 27 & 24 \\
$\quad$ Mild & 10 & 11 \\
Severe & 37 & 35 \\
$\quad$ Total & & \\
Distribution of atrophy: & 17 & 17 \\
$\quad$ Generalised & 7 & 9 \\
$\quad$ Central & 10 & 7 \\
Peripheral & 3 & 2 \\
$\quad$ Focal or lateralised & 37 & 35 \\
$\quad$ Total & & \\
\hline
\end{tabular}

Three of the patients showed mild dementia, and one a dyspraxia; no comparable cerebral defects were present in controls. Reflex asymmetry in the limbs was present in five patients, without limb weakness.

The main findings in the CT scans are summarised in table 4. Ischaemic lesions were present in 13 patients compared with two controls; this difference is significant at the 0.005 level. (chi square test with Yates' correction). Lacunar infarcts were present in seven patients and larger cerebral infarcts in four patients. In three cases the infarcts were multiple (fig). Periventricular white-matter low attenuation alone was seen in three patients; it accompanied infarction in five others. In the control group no 

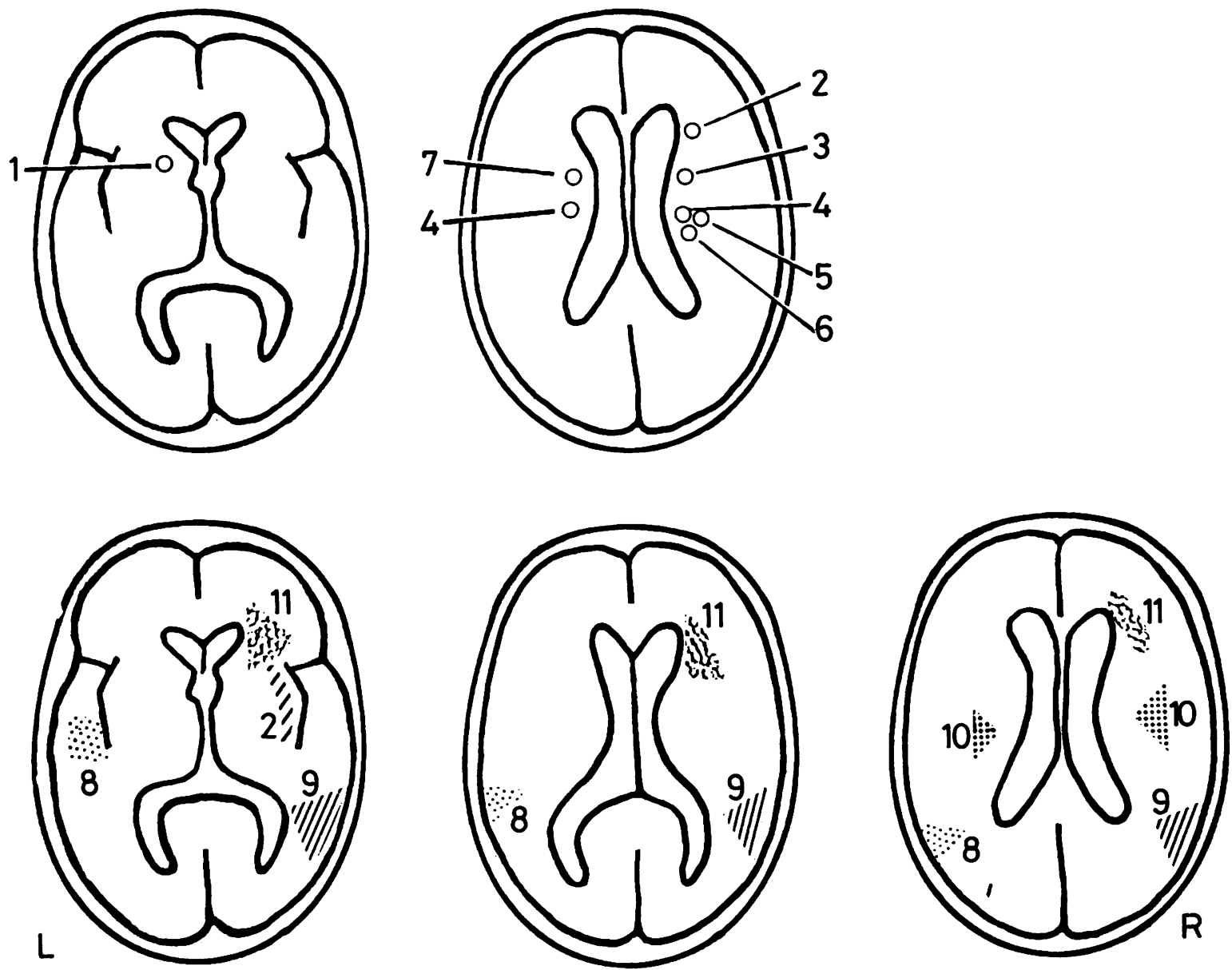

Fig Tracings from CT scans to show size and position of infarcts in 10 epileptic patients (1-10) and in one control (11). Circles indicate lacunar infarcts; shaded and cross-hatched areas indicate cerebral infarcts. In Case 8 the infarct had produced marked focal atrophy extending to the Sylvian fissure.

lacunar infarcts were found but a cerebral infarct was present in one case and white-matter low attenuation in another. In contrast to the ischaemic lesions, there was no significant difference in the severity or site of cerebral atrophy in patients and controls. Measurements of anterior horn width, septum-caudate distance, minimum cella media distance, third ventricular width, Evans ratio and cella media index also failed to show differences between the two groups. There were, however, some changes in these measurements with increasing age in both groups. These will be the subject of a separate report.

In table 5, the clinical features of the 13 patients with ischaemic lesions on CT scanning are compared with those of the 61 patients without lesions. While there was no difference in sex ratios, it can be seen that both the median age of onset of seizures and the median age at presentation were higher in those with ischaemic lesions. Indeed, only one of the patients

Table 5 Clinical features of 13 patients with and 61 patients without ischaemic lesions on CT scanning

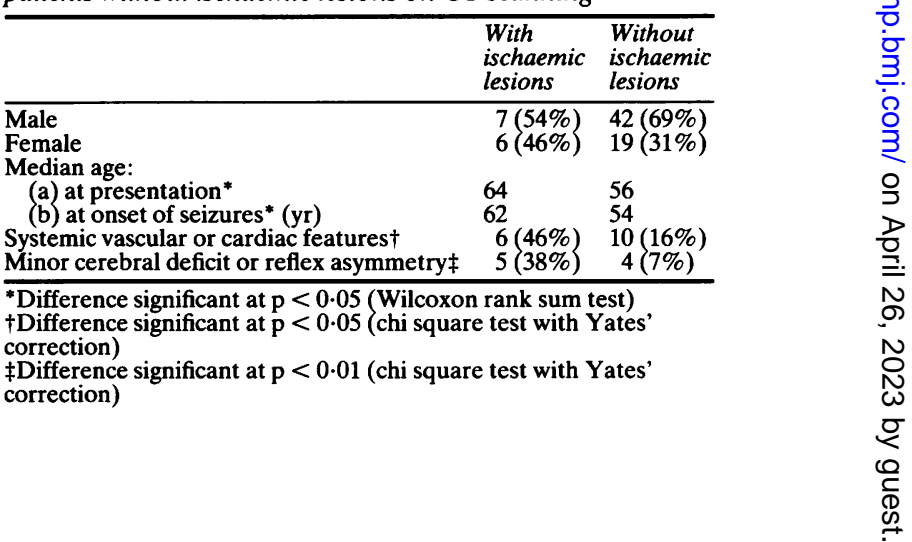


Table 6 Features of epilepsy in 13 patients with and 61 patients without ischaemic lesions on CT scanning

\begin{tabular}{|c|c|c|}
\hline & $\begin{array}{l}\text { With } \\
\text { ischaemic } \\
\text { lesions }\end{array}$ & $\begin{array}{l}\text { Without } \\
\text { ischaemic } \\
\text { lesions }\end{array}$ \\
\hline $\begin{array}{l}\text { Seizure type: } \\
\text { Generalised tonic-clonic } \\
\text { Secondary generalised tonic-clonic } \\
\text { Partial seizures (simple or complex) } \\
\text { Mixed seizures types } \\
\text { Unclassified }\end{array}$ & $\begin{array}{l}6(46 \%) \\
3(23 \%) \\
2(15 \%) \\
2(15 \%) \\
0(0 \%)\end{array}$ & $\begin{aligned} & 27(44 \%) \\
& 5(8 \%) \\
& 19(32 \%) \\
& 6(10 \%) \\
& 4(7 \%)\end{aligned}$ \\
\hline $\begin{array}{l}\text { Seizure No. (at presentation): } \\
\text { Single } \\
\text { Multiple }\end{array}$ & $\begin{array}{r}3(23 \%) \\
10(77 \%)\end{array}$ & $\begin{array}{l}14(23 \%) \\
47(77 \%)\end{array}$ \\
\hline $\begin{array}{l}\text { EEG findings:* } \\
\text { Normal } \\
\text { Minor changes only } \\
\text { Focal changes } \\
\text { Generalised changes }\end{array}$ & $\begin{array}{l}7(58 \%) \\
0(0 \%) \\
2(17 \%) \\
3(25 \%)\end{array}$ & $\begin{array}{c}29(50 \%) \\
10(17 \%) \\
16(28 \%) \\
3(5 \%)\end{array}$ \\
\hline
\end{tabular}

*EEG performed in 70 patients

with ischaemic lesions had developed seizures below the age of 55 , whereas $52 \%$ of those without ischaemic lesions had done so. While there was a higher incidence of systemic vascular features and of minor neurological abnormalities in those with ischaemic lesions, there were six patients in this group without any clinical evidence of underlying vascular disease. In these cases the patient's age and CT scan provided the only clues to the aetiology of the epilepsy. Two representative examples are summarised below.

Miss KB aged 67 years (MH No. 277778) had a 5-month history of seizures, occurring in clusters, in which she experienced briefly a peculiar, indescribable smell, sometimes associated with jumbled speech or with tingling in one arm. Neurological and cardiovascular examination and the EEG were normal. The CT scan showed lacunar infarcts in the region of the right and left corona radiata (Case 4, fig). The attacks ceased on carbamazepine $100 \mathrm{mg}$ bd.

Mr AG aged 70 years (NH No. B20525) had a 9-month history of three nocturnal grand mal convulsions followed by confusion and automatism. Neurological and cardiovascular examination and the EEG were normal. The CT scan showed periventricular white-matter low attenuation and a lacunar infarct in the region of the right corona radiata (Case 5, fig). The attacks were controlled by primidone $250 \mathrm{mg}$ bd.

In respect of the epilepsy itself, there were no features which distinguished those with ischaemic lesions from those without. Table 6 summarises the type and number of seizures and the EEG findings in each group, and it can be seen that there were no important differences between the two.

\section{Discussion}

The traditional view that epilepsy of late onset is usually due to cerebral tumour is incorrect, and both in this study and others ${ }^{3-12}$ tumours have been found in only a small proportion of cases (10-25\%). The role of cerebral vascular disease, however, has proved much more difficult to assess; this is due largely to problems in detection, patient selection and to the lack of controlled data. Cerebral vascular disease may be clinically silent or subtle in its manifestations, and prior to the advent of CT scanning diagnosis was sometimes difficult. Previous studies generally have been either of patients with gross cerebral vascular disease (stroke, etc) ${ }^{3} 5>8$ 13-19 or of those with systemic vascular disease (for example, hypertension) on the assumption that this is associated with cerebral vascular disease..$^{11} 1220 \mathrm{~A}$ few studies using invasive neuroradiological techniques have been carried out but these were necessarily of highly selected populations. ${ }^{6} 9112122$ The results of these investigations have differed widely and the incidence of cerebral vascular disease in groups of late-onset epileptics has been found variously to be between 0 and $77 \%$. In no previous report has a control group been included, in spite of the high prevalence of vascular disease in an ageing population.

With the introduction of CT scanning, cerebral vascular disease can now be more securely demonstrated, and here we have used this technique to assess the prevalence and nature of cerebral vascular changes in a group of patients presenting with lateonset seizures without a clinically obvious cause, and in age and sex-matched controls. Ischaemic lesions were found on CT scanning in $18 \%$ of the patients, significantly more than in the control group. This figure may be compared with the finding of infarction in 11 out of 220 patients with recent-onset or established epilepsy studied by CT scanning $;{ }^{23}$ in this study the patients' ages ranged from 8-76 years (average age 36 years) but the ages of those with infarcts were not given. In our own cases there was a significant association between ischaemic lesions in the CT scan and cardiac or systemic vascular disease, but as these latter conditions were equally common in the control and patient groups, they proved in themselves a poor guide to the presence of cerebral vascular disease. Ischaemic lesions were also found more commonly in those patients with minor neurological abnormalities on clinical examination. Nevertheless, in approximately half of the patients with ischaemic lesions there was no clinical evidence of cardiac, systemic vascular or neurological abnormality, and the epilepsy was the only manifestation of cerebral dysfunction.

No patient under the age of 55 years at presentation had CT evidence of cerebral vascular disease, and ischaemic lesions were found in only one patient 
whose seizures began before this age. No sex differences nor any difference in the type of epilepsy or EEG abnormality were found when those with and without ischaemic lesions were compared, and it is noteworthy that neither clinical nor EEG features suggestive of focal cerebral pathology proved useful in predicting the presence of ischaemic lesions in the CT scan.

Lacunar infarction was found in seven patients, although epilepsy is not usually considered to result from this. ${ }^{24}$ It is likely that these lacunes were indicative of more widespread cerebral vascular disease $^{25}$ rather than that they were directly responsible for the epilepsy, but further study of this association is needed. Only two of the seven patients with lacunes were hypertensive, and a loose association has been noted by others. ${ }^{25}$ Periventricular white-matter low attenuation on the $C T$ scan was noted in eight patients; this is a manifestation of cerebral vascular disease often unsuspected on clinical grounds, and only four of the eight patients had systemic vascular or cardiac disease. Cerebral infarction was found in three patients and in one control, and was associated with systemic vascular or cardiac disease in three. None of these patients with cerebral infarction had a history of stroke.

"Cerebral atrophy" on the CT scan was common in both the patient and the control groups. Neither its presence, site or severity showed any correlation with the neurological or vascular status of the patients, and it must be considered a finding of very little significance in an individual case. It should be noted that previous reports of its association with epilepsy have usually failed to include control data. ${ }^{26-29}$

CT scanning is at present the best widely available non-invasive method of detecting discrete cerebral vascular lesions which may often, as we have shown, be clinically unsuspected. Nevertheless, a number of patients with cerebral vascular disease (as demonstrated by cerebral angiography for instance) have a normal CT scan, and the proportion of patients with ischaemic lesions in this study should be considered a minimum estimate of those with cerebral vascular disease. As scanning methods improve and newer techniques (for example, NMR) are introduced, the relationship of epilepsy and cerebral vascular disease will be more exactly defined.

We thank colleagues for permission to review their patients. We are particularly grateful to Dr IF Moseley for helpful criticism and advice. The study was supported by a generous grant from The Sir Jules Thorn Charitable Trust.

\section{References}

${ }^{1}$ Cull RE, Gilliatt RW, Quy RJ, Willison RG. Prolonged observation and EEG monitoring of epileptics. In: $A$ Textbook of Epilepsy, 2nd Ed. Richens A, Laidlaw J, eds. Edinburgh: Churchill Livingstone, 1982;p.21126.

${ }^{2}$ Gyldensted C. Measurement of the normal ventricular system and hemispheric sulci of 100 adults with computed tomography. Neuroradiology 1977;14: 183-92.

${ }^{3}$ Bonduelle M, Sallou G, Guillard J. Etude de 51 dossiers d'épilepsie ayant debate après 60 ans. Sem Hop Paris 1970;46:3141-4.

${ }^{4}$ Carney LR, Hudgins RL, Espinosa RE, Klass DW. Seizures beginning after the age of 60 . Arch Intern Med 1969;124:707-9.

${ }^{5}$ Courjon J, Artu F, Zeskov P. A propos des crises d'épilepsie apparaissant après 60 ans observées en clientèle de neurologie dans un service de neurochirurgie. Sem Hop Paris 1970;46:3129-32.

${ }^{6}$ Dimsdale H. Epilepsy of late onset in the light of modern diagnostic procedures. Br Med J 1956;1:1214-6.

${ }^{7}$ Dusaucy-Bauloye A, Sorel L. Considérations au sujet de 213 cas d'épilepsie tardive non tumorale. Acta Neurol Psychiat Belg 1959;59:448-64.

${ }^{8}$ Hildick-Smith M. Epilepsy in the elderly. Age Ageing 1974;3:203-8.

${ }^{9}$ Raynor RB, Paine RS, Carmichael EA. Epilepsy of late onset. Neurology (Minneap) 1959;9:111-7.

${ }^{10}$ Roberts MA, Godfrey JW, Caird FI. Epileptic seizures in the elderly: 1 . Aetiology and type of seizure. Age Ageing 1982;11:24-8.

${ }^{11}$ Sheehan S. One thousand cases of late onset epilepsy. Irish J Med Sci 1958;261-72.

${ }^{12}$ White PT, Bailey AA, Bickford RG. Epileptic disorders in the aged. Neurology (Minneap) 1953;3:674-8.

${ }^{13}$ Dodge P, Richardson E, Victor M. Recurrent convulsive seizures as a sequel to cerebral infarction: a clinical and pathological study. Brain 1954;77:610-38.

${ }^{14}$ Fuerstein J, Weber M, Kurtz D, Rohmer F. Étude statistique des crises épileptiques apparaissant après d'age 60 ans. Sem Hop Paris 1970;46:3115-28.

${ }^{15}$ Louis S, McDowell F. Epileptic seizures in nonembolic cerebral infarction. Arch Neurol 1967;17:414-8.

${ }^{16}$ Marquardson J. The natural history of acute cerebrovascular disease. Acta Neurol Scand 1969;45:Suppl. 38.

${ }^{17}$ Richardson EP, Dodge PR. Epilepsy in cerebral vascular disease. Epilepsia 1954;3:49-65.

${ }^{18}$ Schold C, Yarnell PR, Earnest MP. Origin of seizures in elderly patients. JAMA 1977;238:1177-8.

${ }^{19}$ Webster J, Gurdjian E, Martin F. Carotid Artery Occlusion. Neurology (Minneap) 1956;6:491-502.

${ }^{20}$ Vercelletto P, Delobel R. Étude des facteurs etiologiques et prognostiques dans les épilepsies debutent après 60 ans. Sem Hop Paris 1970;46:3133-7.

${ }^{21}$ Hurwitz LJ, Groch SN, Wright IS, McDowell FH. Carotoid artery occlusive syndrome. Arch Neurol 1959;1:491-501.

${ }^{22}$ Cocito L, Favale E, Reni L. Epileptic seizures in cerebral arterial occlusive disease. Stroke 1982;13:189-95.

${ }^{23}$ Young AC, Borg Costanzi J, Mohr PD, Forbes W. Is 
routine computerised axial tomography in epilepsy worth while? Lancet 1982;ii:1446-7.

${ }^{24}$ Fisher CM. Lacunar strokes and infarcts: a review. Neurology (Minneap) 1982;32:871-6.

${ }^{25}$ Miller V. Lacunar stroke: a reassessment. Arch Neurol 1983;40:129-34.

${ }^{26}$ Cala LA, Mastaglia FL, Woodings TL. Computerized tomography of the cranium in patients with epilepsy: a preliminary report. Clin Exper Neurol 1977;14:237-44.

${ }^{27}$ Gastaut H. Conclusions: computerized transverse axial tomography in epilepsy. Epilepsia 1976;17:337-8.

${ }^{28}$ Gastaut H, Gastaut JL. Computerised transverse axial tomography in epilepsy. Epilepsia 1976;17:325-36.

${ }^{29}$ McGahan JP, Dublin AB, Hill RP. The evaluation of seizure disorders by computerized tomography. $J$ Neurosurg 1979;50:328-32. 